\title{
Phase II study of gemcitabine and bexarotene (GEMBEX) in the treatment of cutaneous T-cell lymphoma
}

\begin{abstract}
T Illidge ${ }^{\star 1}$, C Chan ${ }^{1}$, N Counsell ${ }^{2}$, S Morris ${ }^{3}$, J Scarisbrick ${ }^{4}$, D Gilson ${ }^{5}$, B Popova ${ }^{2}$, P Patrick ${ }^{2}$, P Smith ${ }^{2}$, S Whittaker ${ }^{6}$ and R Cowan ${ }^{1}$

${ }^{1}$ Manchester Academic Health Science Centre, Institute of Cancer Sciences, University of Manchester, The Christie, Wilmslow Road, Manchester, M20 4BX, UK; ${ }^{2}$ Cancer Research UK and University College London Cancer Trials Centre, 90 Tottenham Court Road, London W1T 4TJ, UK; ${ }^{3}$ Guys and St. Thomas' Hospital, Lambeth Palace Road, London SE1 7EH, UK; ${ }^{4}$ University Hospitals Birmingham NHS Foundation Trust, Queen Elizabeth Medical Centre, Queen Elizabeth Hospital, Birmingham B15 2TH, UK; ${ }^{5}$ St James's Institute of Oncology, St James's University Hospital, Beckett Street, Leeds LS9 7TF, UK and ' ${ }^{6}$ St John's Institute of Dermatology, Guys and St Thomas NHS Foundation Trust, Lambeth Palace Road, London SE1 7EH, UK
\end{abstract}

Background: Both gemcitabine and bexarotene are established single agents for the treatment of cutaneous T-cell lymphoma (CTCL). We investigated the feasibility and efficacy of combining these drugs in a single-arm phase II study.

Methods: Cutaneous T-cell lymphoma patients who had failed standard skin-directed therapy and at least one prior systemic therapy were given four cycles of gemcitabine and concurrent bexarotene for 12 weeks. Responders were continued on bexarotene maintenance until disease progression or unacceptable toxicity.

Results: The median age was 65 years, stage IB $(n=5)$, stage IIA $(n=2)$, stage IIB $(n=8)$, stage III $(n=8)$ and stage IVA $(n=12)$, 17 patients were erythrodermic, 17 patients were B1, and 10 patients were both erythrodermic and B1. Thirty (86\%) patients completed four cycles of gemcitabine. In all, $80.0 \%$ of patients demonstrated a reduction in modified Severity-Weighted Assessment Tool (mSWAT) score although the objective disease response rate at 12 weeks was 31\% (partial response (PR) 31\%) and at 24 weeks 14\% (PR 14\%, stable disease (SD) 23\%, progressive disease (PD) 54\%, not evaluable 9\%). Median progression-free survival was 5.3 months and median overall survival was 21.2 months.

Conclusion: The overall response rate of the combination did not reach the specified target to proceed further and is lower than that previously reported for gemcitabine as a single agent.

Peripheral T-cell (PTCL) and cutaneous T-cell lymphomas (CTCL) account for between $5 \%$ and $10 \%$ of all malignant lymphomas in western countries (Jaffe et al, 2001). The estimated incidence rate of CTCL in the United States is 0.4 per 100000 person-years (Weinstock and Horm, 1988). A variety of chemotherapy regimens have demonstrated high response rates in small patient groups with CTCL, albeit that the duration of responses is usually short lived. Some of the cytotoxic drugs that have demonstrated efficacy and have been adopted into routine clinical practice include weekly, low-dose methotrexate (Zackheim and Epstein, 1989), purine analogues (2-deoxycoformycin (pentostatin), 2-chlorodeoxyadenosine and fludarabine) (Bunn et al, 1994; Kurzrock et al, 1999), pegylated liposomal Doxorubicin (Rosen and Foss, 1995; Kim et al, 1999), Denileukin diftitox (DAB389IL-2) (Saleh et al, 1998) and gemcitabine (Zinzani et al, 2000; Marchi et al, 2005; Zinzani et al, 2010).

Gemcitabine $\left(2^{\prime} 2^{\prime}\right.$-difluorodeoxycitidine $)$ is a novel pyrimidine anti-metabolite and in a phase II study of 30 patients confirmed 
high activity in pre-treated CTCL and a 70\% response rate (partial response (PR) 60\%, complete response (CR) 10\%) (Zinzani et al, 2000). This was confirmed in a further phase II study of gemcitabine monotherapy in 25 CTCL patients, which demonstrated a $68 \%$ overall response rate (Duvic et al, 2006). Given this published activity and manageable toxicity profile, gemcitabine is increasingly being used in the treatment of T-cell lymphoma (Marchi et al, 2005). Other novel approaches to the treatment of CTCL have included bexarotene, which is a synthetic ligand for the rexinoid X receptor (RXR). Bexarotene has been shown to be a highly active agent in the treatment of relapsed or refractory CTCL with a response rate of $\sim 45 \%$ (Duvic et al, 2001a, b), which led to the US and EU regulatory authorities granting approval for the treatment of relapsed CTCL that has failed skin-directed therapies. Further confirmatory studies demonstrated a response rate of $44 \%$ which was higher in advanced disease (47\%) and those on combination therapy $(52 \%)$. The highest response rate was seen in those with Sézary syndrome (69\%) (Abbott et al, 2009).

Given that gemcitabine and bexarotene have become established in routine clinical management of CTCL and are being used in combination in clinical practice, we elected to investigate a combination approach of these two active drugs in a phase II clinical trial. The study hypotheses were that the different mechanisms of action would lead to gemcitabine reducing disease burden rapidly, while bexarotene would potentially lead to an improved quality and durability of clinical response. Here, we describe the results of a phase II study of gemcitabine and bexarotene combination (GemBex) performed by the UK National Cancer Research Institute (NCRI).

\section{PATIENTS AND METHODS}

Patients' selection. Patients with stages IB to IVB histologically confirmed CTCL (including mycosis fungoides (MF) and Sézary syndrome) were enrolled in the study. Eligible patients were $\geqslant 18$ years, had failed standard skin-directed therapy and at least one prior systemic therapy, and had anticipated life expectancy $>6$ months. Study entry required ECOG performance status $\leqslant 1$, adequate organ function (haemoglobin $\geqslant 9.0 \mathrm{~g} \mathrm{dl}^{-1}$, absolute neutrophil count $>1.5 \times 10^{9}$ per litre, platelets $\geqslant 100 \times 10^{9}$ per litre, total bilirubin $\leqslant 1.25 \times$ upper limit of normal (ULN), AST and ALT $\leqslant 2.0 \times \quad \mathrm{ULN}$, and serum creatinine $\leqslant 2.0 \times \mathrm{ULN})$. Patients with primary cutaneous $\mathrm{CD} 30+(\mathrm{Kil}+\mathrm{ve})$ anaplastic large cell lymphoma were excluded from the study as were patients who had previously failed bexarotene treatment, or had a history of pancreatitis, biliary tract disease or uncontrolled diabetes mellitus. The use of topical or systemic steroids was avoided during the study, with the exception of those patients who had been on a stable, low dose $(<20 \mathrm{mg})$ of steroid for 3 months before study entry (see protocol in Supplementary data).

Study design and treatment. The study was a two-stage, multicentre, phase II open-label, non-randomised, single-arm trial to assess the feasibility and efficacy of using a combination of gemcitabine and bexarotene for the treatment of CTCL. Research ethics and regulatory approvals (MREC number 06/Q1206/65; UKCRN ID 1756) for the trial were obtained before patient enrollment. Written informed consent to participate in the trial was obtained from all patients before any study-specific procedures were undertaken. Patient registration and trial management were performed by the Cancer Research United Kingdom and University College London Cancer Trials Centre (ClinicalTrials.gov identifier: NCT00660231). All authors had access to primary clinical trial data.

All patients were planned to receive gemcitabine $1000 \mathrm{mg} \mathrm{m}^{-2}$ i.v. on days 1 and 8 of a 21-day cycle for four cycles (total duration of 12 weeks) during which bexarotene $300 \mathrm{mg} \mathrm{m}^{-2}$ p.o. daily was administered concurrently, increased from $150 \mathrm{mg} \mathrm{m}^{-2}$ p.o. daily in the first 2 weeks if tolerated. At 12 weeks, responding patients were maintained on bexarotene $300 \mathrm{mg} \mathrm{m}^{-2}$ p.o. daily until disease progression or the treatment was no longer tolerated. The dose could be reduced due to toxicity, and if further toxicity occurred then the patient was withdrawn. Lipid-lowering therapy with fenofibrate and thyroxine was started 1 week before and on the day of initiation of bexarotene, respectively. A flow diagram outlining the management of thyroid and lipid abnormalities during bexarotene treatment is shown in Figure 1. Both fenofibrate and thyroxine were continued concomitantly with bexarotene.

Tumour assessments. Within 2 weeks of starting treatment, during the initial 12-week combination and subsequently at weeks 13,17 , and 24 , and every 8 weeks thereafter, patients underwent: physical examination, disease assessment including modified Severity-Weighted Assessment Tool (mSWAT) score that represents the product of the \%TBSA involvement of each lesion type multiplied by a weighting factor (Stevens et al, 2002), concomitant medications, body weight, vital signs, ECOG performance status, full blood count with differential and CD4 count, biochemistry, lipid profile, CPK and thyroid function, and quality of life (QoL) assessments using a visual analogue score (VAS), the Skindex 29 and EORTC QLQ-C30 questionnaires. CT scan of the chest, abdomen and pelvis, and photography of lesions were evaluated before study entry, and at weeks 13 and 24. Medical history, histology of skin, lymph node and peripheral blood, height, urinalysis, urine pregnancy test (if applicable) and ECG were also evaluated before study entry. Adverse events were recorded during the trial and 30 days after finishing treatment or until all toxicities

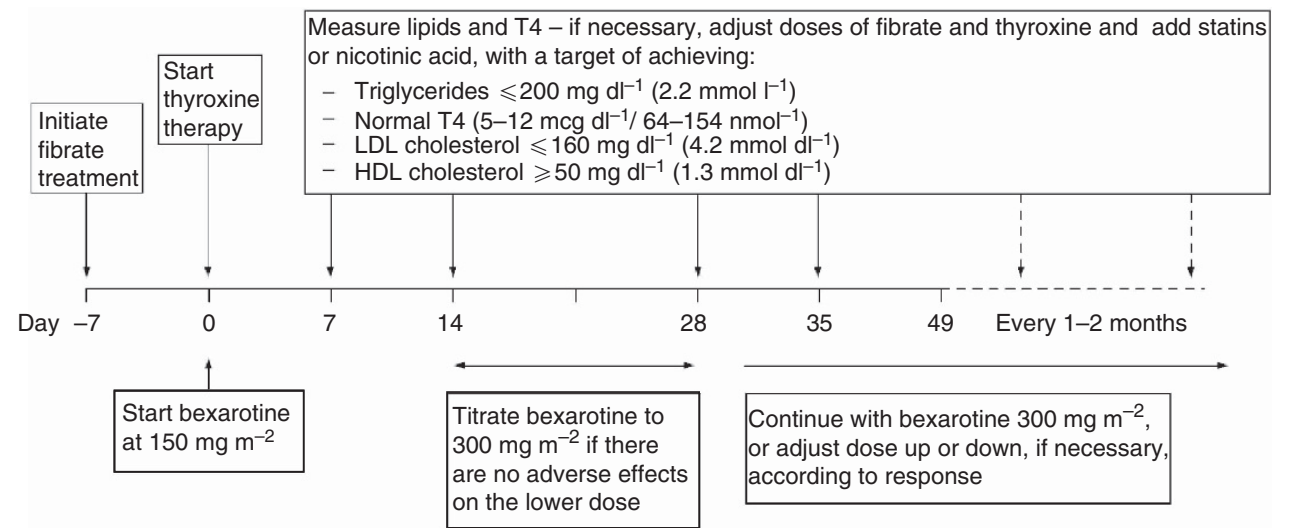

Figure 1. Management of thyroid/lipid abnormalities during bexarotene therapy. 
had been resolved, and graded using the National Cancer Institute Common Terminology Criteria of Adverse Events (version 3).

Statistical consideration. The primary end point was the rate of objective response assessed at 24 weeks, defined as the proportion of patients with confirmed $\mathrm{CR}$, clinical complete response (CCR) or PR, as determined by the Objective Primary Disease Response Evaluation Criteria (OPDREC). These criteria combine the response observed in skin, lymph nodes, viscera and blood to a global response category. To be defined as CCR, CR or PR, the response must be confirmed with a repeat assessment at least 1 month after the initial assessment (Whittaker et al, 2010).

A Simon (1989) optimal two-stage design was used, assuming that a response rate at 24 weeks of $<50 \%$ would not be of interest to pursue, and a target response rate of $\geqslant 65 \%$ with gemcitabine and bexarotene would be of interest to pursue. Using a one-sided $10 \%$ significance level and $90 \%$ power, the target accrual was 35 patients in the first stage, then an additional 49 in the second stage if $\geqslant 19$ first-stage patients had responded at week 24 .

Other end points included objective disease control (CR, CCR, $\mathrm{PR}$, or stable disease (SD)), progression-free (PFS) and overall survival (OS), adverse events, and change from baseline in mSWAT value and QoL assessments. The as-treated population, including all enrolled patients that received at least one dose of study treatment, was used for the analysis of all end points unless otherwise stated.

\section{RESULTS}

Patient characteristics. Thirty-six patients were recruited (July 2008 to March 2011) from 9 centres across the UK National Cancer Research Network. Table 1 shows the baseline characteristics. Figure 2 (CONSORT diagram) shows the number of patients who started and continued trial treatment. The median age of the patients was 65 years (range 38-83), with 25 males (69.4\%) and 11 females $(30.6 \%)$. The majority of patients had advanced stage disease with 11 tumour stage T3 patients (30.6\%) and $17 \mathrm{~T} 4$ patients $(47.2 \%), 9$ nodal stage N1 $(25.0 \%), \mathrm{N} 2(5.6 \%)$ and N3 (30.6\%). Seventeen patients (47.2\%) were erythrodermic and ten patients $(27.8 \%)$ were both erythrodermic and B1. At baseline, the median pruritus score was high at 7.5 (range $0-10$ ) and the median mSWAT score was 103 (range 13-203).

Treatment compliance. Thirty-five patients started trial treatment; of the as-treated population thirty $(85.7 \%)$ patients received four cycles of gemcitabine and bexarotene combination, one $(2.9 \%)$ received three cycles, three $(8.6 \%)$ received two cycles and one $(2.9 \%)$ received only one cycle. During the four cycles of combination treatment, only six $(17.1 \%)$ patients did not require a dose reduction or delay in bexarotene. In all, 3 (8.6\%) patients remain on bexarotene maintenance treatment at the time of reporting (>19 months), however, 24 (68.6\%) patients stopped protocol treatment due to disease progression, $4(11.4 \%)$ due to unacceptable toxicity, 2 (5.7\%) due to symptomatic deterioration (defined as global deterioration of health status requiring discontinuation of treatment without objective evidence of disease progression), 1 (2.9\%) changed to have extracorporeal photopheresis and 1 (2.9\%) died due to Staphylococcus aureus infection associated with Sézary syndrome. Median time on trial treatment was 19.9 weeks. Appendix Table 1 shows gemcitabine and bexarotene dose information.

Efficacy. Eleven patients (31.4\%) had responded at week 12, after four cycles of combination treatment (11 PR, 14 SD, 6 progressive disease (PD), 4 not evaluable). Patients with erythrodermic disease had a lower but non-significant response rate than those with a non-erythrodermic phenotype (3 out of 17 (18\%) vs 8 out of
Table 1. Baseline characteristics, enrolled patients

\begin{tabular}{|l|c|}
\hline & GemBex $(\boldsymbol{n}=\mathbf{3 6})^{\mathrm{a}}$ \\
\hline Variable & Median (range) \\
\hline Age at random assignment, years & $65(38-83)$ \\
\hline Pruritis (0-10 continuous scale) & $7.5(0-10)$ \\
\hline mSWAT score & $103(13-203)$ \\
\hline \multicolumn{2}{|l|}{ No. (\%) } \\
\hline Gender & $25(69.4)$ \\
\hline Male & $11(30.6)$ \\
\hline Female &
\end{tabular}

\section{ECOG performance status}

\begin{tabular}{|l|l|}
\hline 0 & $20(55.6)$ \\
1 & $16(44.4)$
\end{tabular}

\section{Clinical stage at study entry}

\begin{tabular}{|l|c}
\hline $\mathrm{Ib}$ & $5(13.9)$ \\
$\mathrm{Ila}$ & $2(5.6)$ \\
$\mathrm{Ilb}$ & $8(22.2)$ \\
$\mathrm{III}$ & $8(22.2)$ \\
$\mathrm{IVa}$ & $13(36.1)$
\end{tabular}

\section{T skin}

\begin{tabular}{|r|r}
\hline T1 & $1(2.8)$ \\
T2 & $7(19.4)$ \\
T3 & $11(30.6)$ \\
T4 & $17(47.2)$ \\
\hline
\end{tabular}

\section{N lymph nodes}

\begin{tabular}{|c|c|}
\hline N0 & $14(38.9)$ \\
N1 & $9(25.0)$ \\
N2 & $2(5.6)$ \\
N3 & $11(30.6)$ \\
\hline
\end{tabular}

B peripheral blood

\begin{tabular}{|l|c|}
\hline B0 & $18(51.4)$ \\
B1 & $17(48.6)$ \\
Missing & 1 \\
\hline
\end{tabular}

$M$ visceral organ involvement

\begin{tabular}{|c|c|}
\hline M0 & $36(100.0)$ \\
M1 & $0(0.0)$ \\
\hline
\end{tabular}

Lymphadenopathy

\begin{tabular}{|l|l|}
\hline No & $12(33.3)$ \\
Yes & $24(66.7)$ \\
\hline
\end{tabular}

\section{Erythrodermic}

\begin{tabular}{|l|l}
\hline No & $19(52.8)$ \\
Yes & $17(47.2)$ \\
\hline
\end{tabular}

Abbreviations: $\quad E C O G=$ Eastern $\quad$ Cooperative Oncology Group; $m S W A T=$ modified Severity-Weighted Assessment Tool.

ane patient was ineligible and withdrawn before treatment start

19 (42\%), respectively, $P=0.22$ ). The Waterfall plot (Figure 3) demonstrates an improvement in mSWAT score in 28 patients $(80.0 \%)$ at week 12 compared with baseline mSWAT score. However, the overall objective response rate (ORR) was $14.3 \%$ at 24 weeks (5 PR, 8 SD and 19 PD, 3 not evaluable).

After a median follow-up of 16.4 months from first day of treatment (censoring those who had died), 30 patients $(85.7 \%)$ had 
either died $(n=15)$ or were alive with disease progression $(n=15)$, with a median PFS of 5.3 months. Progression-free survival was similar in patients with erythrodermic and non-erythrodermic disease (median PFS 5.3 months vs 4.6 months, respectively, $P=0.87)$. Of the fifteen patients $(42.9 \%)$ who had died, the cause of death was CTCL $(n=13)$, CTCL and treatment-related toxicity $(n=1)$, and hepatorenal failure secondary to sepsis complicated by Sézary syndrome $(n=1)$, with median OS of 21.2 months. Figure 4 shows the PFS and OS curves.

Toxicity. The toxicity of treatment is shown in Tables 2 and 3. Overall, twenty-five (71.4\%) patients suffered from a grade 3 or 4 adverse event during the four cycles of combination treatment (8 $(22.9 \%)$ grade 4$)$. Six (25.0\%) of the twenty-four patients who continued with bexarotene maintenance suffered from a grade 3 or 4 adverse event, including 1 (4.2\%) of grade 4 . Fourteen patients (40.0\%) suffered from a grade 3 or 4 haematological toxicity during combination treatment, including $4(11.4 \%)$ of grade 4 , with 1 $(4.2 \%)$ additional grade 3 case during maintenance.

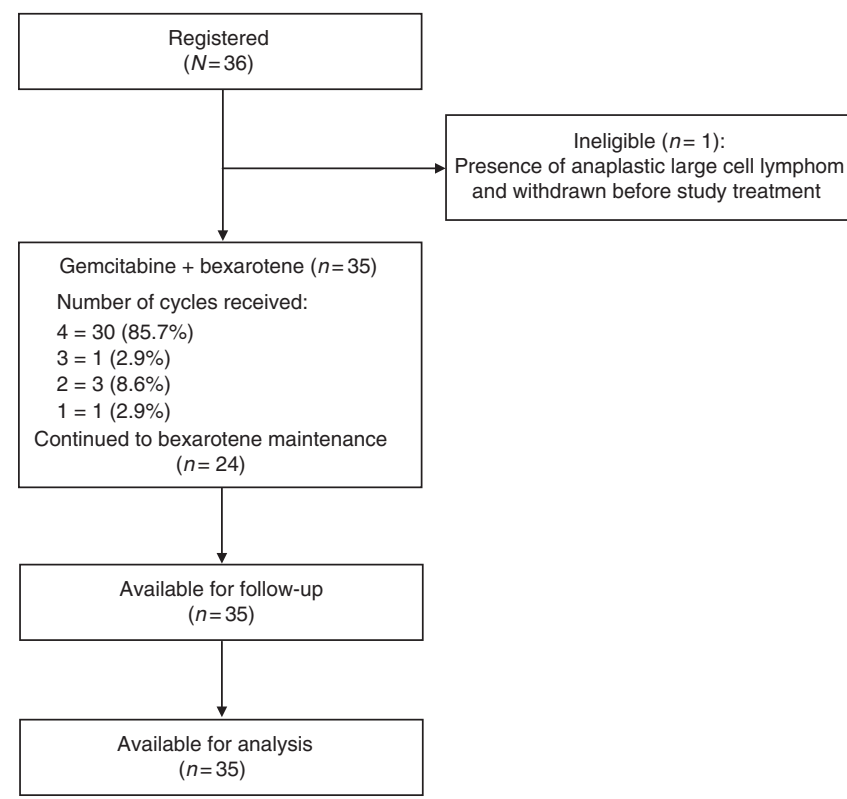

Figure 2. CONSORT diagram outlining the number of patients and cycles of treatment received.
Ten patients $(28.6 \%)$ suffered from grade 3 or 4 hyperlipidaemia during combination treatment, including $3(8.6 \%)$ of grade 4 , with $3(12.5 \%)$ additional grade 3 cases during maintenance. Serum triglyceride levels increased to above $4.5 \mathrm{mmoll}^{-1}$ in $7(20.0 \%$, cycle 1$), 17$ (48.6\%, cycle 2$), 14$ (40.0\%, cycle 3$)$ and 9 ( $25.7 \%$, cycle 4) patients. Median lipid levels rose significantly above baseline by the end of cycle $1\left(+2.91 \mathrm{mmoll}^{-1}, P<0.01\right)$ and remained above baseline after cycle $2\left(+2.59 \mathrm{mmoll}^{-1}, \quad P<0.01\right)$, cycle 3 $\left(+1.82 \mathrm{mmoll}^{-1}, P<0.01\right)$, cycle $4\left(+2.66 \mathrm{mmoll}^{-1}, P<0.01\right)$, at week $17\left(+2.20 \mathrm{mmoll}^{-1}, \quad P<0.01\right)$ and week 24 $\left(+1.43 \mathrm{mmoll}^{-1}, P<0.01\right)$.

Quality of Life. Baseline QoL forms were completed by $77.1 \%$ of patients and results are shown in Appendix Table 2. There was a general improvement in the QoL scores, with a significant decrease in VAS (scale: $0=$ 'no itching' to $10=$ 'unbearable itching') and Skindex Emotions, Symptoms and Functioning scales (scale: $0=$ 'no effect' to $100=$ 'effect experienced all the time') over time (all P's < 0.01). Changes over time in EORTC QLQ-C30 Functional scales and Global Health Status (scale: $0=$ 'low' to $100=$ 'high/ healthy level of functioning') were non-significant (all $P$ 's $\geqslant 0.15$ ).

The change from baseline in mSWAT score at the end of combination treatment was strongly correlated with change in EORTC QLQ-C30 Emotional Functioning $(\rho=-0.715, P<0.01)$, and weakly correlated with Role Functioning $(\rho=-0.342$, $P=0.18)$, SKINDEX Emotions $(\rho=0.427, P=0.09)$, Symptoms ( $\rho=0.401, P=0.11)$ and Functioning $(\rho=0.351, P=0.17)$. There was no correlation with changes in VAS $(\rho=0.082, P=0.77)$, Global Heath Status $(\rho=0.041, P=0.88)$, EORTC QLQ-C30 Physical Functioning $(\rho=-0.097, P=0.70)$, Cognitive Functioning $(\rho=-0.180, P=0.49)$ or Social Functioning $(\rho=0.051$, $P=0.84)$.

\section{DISCUSSION}

Gemcitabine and bexarotene are used as single agents and in combination in routine clinical practice for the treatment of CTCL. We therefore sought to investigate the combination in a multicentre study using strict assessment criteria of the mSWAT scoring system as a measure of response. The major finding to emerge from this study was that although $80.0 \%$ of patients demonstrated a reduction in mSWAT score with the combination of bexarotene and gemcitabine the objective responses and duration of responses

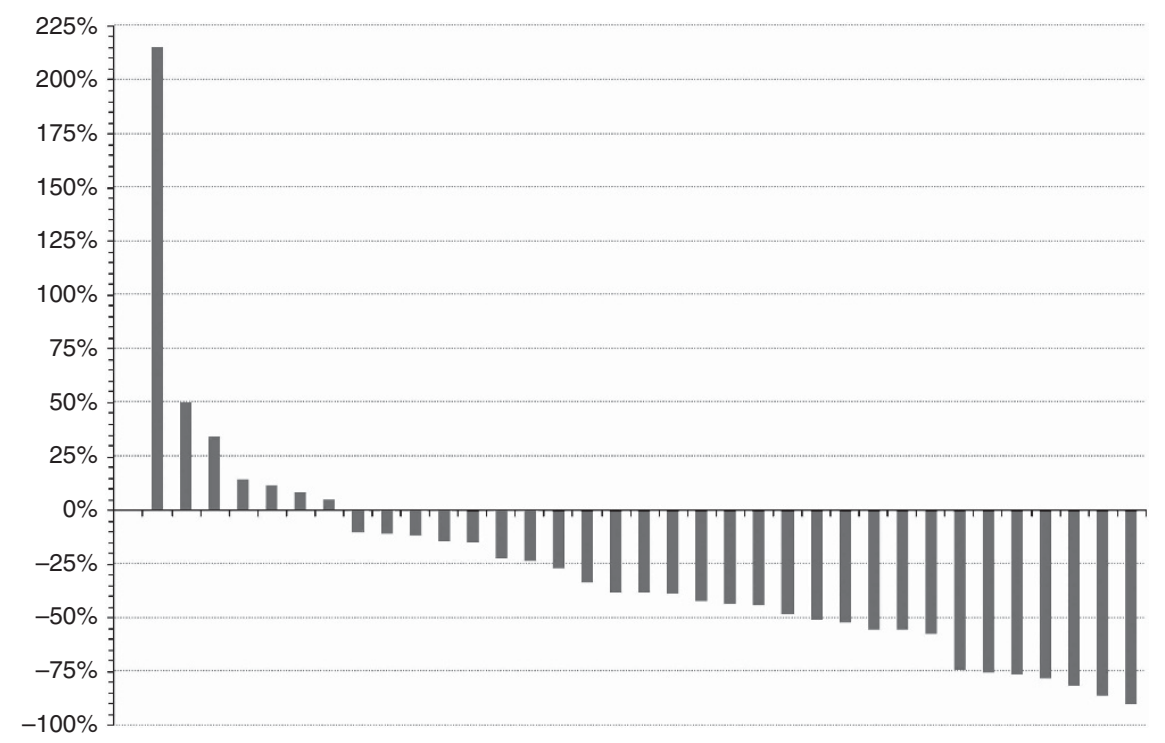

Figure 3. Waterfall plot of percentage change from baseline in mSWAT score at the end of combination treatment, as-treated population. 
A

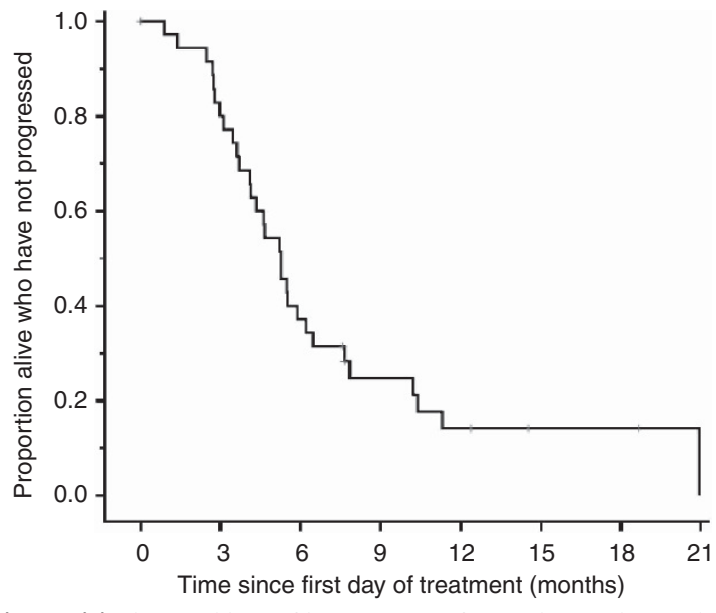

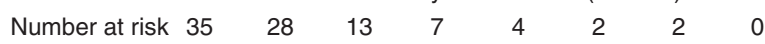

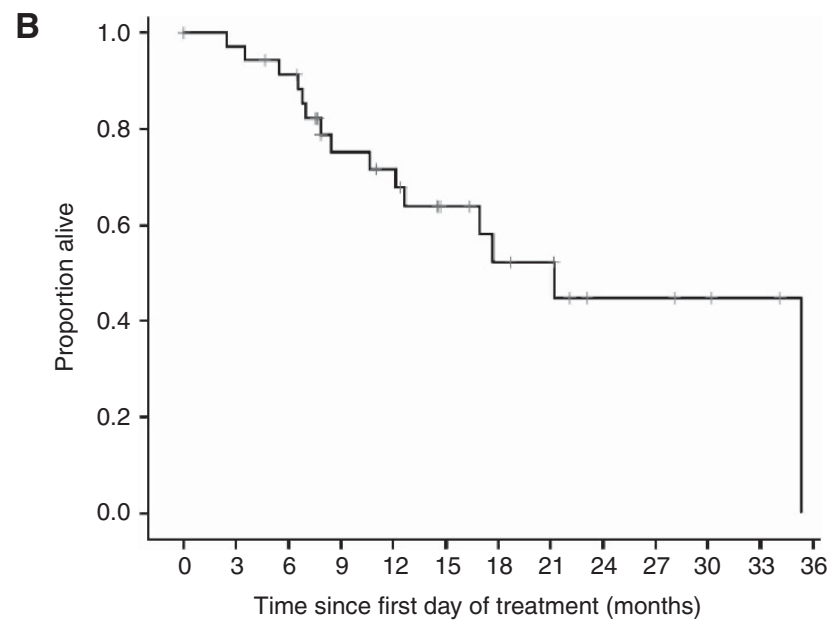

$\begin{array}{llllllllllllll}\text { Number at risk } & 35 & 34 & 31 & 21 & 19 & 12 & 9 & 8 & 4 & 4 & 3 & 2 & 0\end{array}$

Figure 4. (A) Progression-free and (B) overall survival curves, astreated population.

were surprisingly poor at 24 weeks and did not meet the predefined criteria set to proceed to the second stage of the trial. A further important observation from the study was that the combination of these two drugs appears to increase serum triglycerides over and above that seen with bexarotene alone.

A number of systemic agents have been investigated for the treatment of CTCL. Both low-dose methotrexate and pentostatin have shown ORR of $>70 \%$ (Zackheim and Epstein, 1989; Kurzrock et al, 1999), and a phase I trial combining Denileukin diftitox with bexarotene demonstrated an ORR of 67\% (Duvic, 2000). More recently, a phase II EORTC trial demonstrated that pegylated liposomal doxorubicin had an acceptable safety profile and could induce responses in $40 \%$ patients with a median duration of response of 6 months (95\% CI 5.0-10.4 months) (Dummer et al, 2012b). However, most of these clinical studies have recruited low numbers of patients, and the assessment criteria used to define response have been variable, making interpretation difficult to extrapolate to routine clinical practice.

The difficulty in interpreting these small studies is highlighted by the data initially reported for gemcitabine in patients with MF who were included as a subset with nodal PTCL patients. From this study, there is little information on the extent of disease of the MF patients and the mSWAT was not used for the response assessment. While a complete disappearance of skin lesions for at least 4 weeks (CR) is well defined, a PR, defined as reduction of $>50 \%$ of the overall skin involvement (with the disappearance of
Table 2. Reported grade 3 or 4 toxicities during gemcitabine/bexarotene treatment cycles $1-4$ or within 30 days of stopping combination

treatment, as-treated population

\begin{tabular}{|l|c|c|c|}
\hline & $\begin{array}{c}\text { Grade 3 } \\
\mathbf{( N = 3 5 )}\end{array}$ & $\begin{array}{c}\text { Grade 4 } \\
\mathbf{( N = 3 5 )}\end{array}$ & $\begin{array}{c}\text { Total } \\
(\mathbf{N}=35)\end{array}$ \\
\hline & No. (\%) & No. (\%) & No. (\%) \\
\hline $\begin{array}{l}\text { Any toxicity (each patient counted } \\
\text { once) }\end{array}$ & $24(68.6)$ & $8(22.9)$ & $25(71.4)$ \\
\hline Any haematological toxicity (each & $13(37.1)$ & $4(11.4)$ & $14(40.0)$ \\
patient counted once) & & & \\
\hline Neutropaenia & $8(22.9)$ & $3(8.6)$ & $11(31.4)$ \\
Leucopaenia & $4(11.4)$ & $1(2.9)$ & $5(14.3)$ \\
Thrombocytopaenia & $1(2.9)$ & $1(2.9)$ & $2(5.7)$ \\
Anaemia & $1(2.9)$ & $0(0.0)$ & $1(2.9)$ \\
\hline Any non-haematological toxicity & $15(42.9)$ & $4(11.4)$ & $17(48.6)$ \\
(each patient counted once) & & & \\
\hline Hyperlipidaemia & $7(20.0)$ & $3(8.6)$ & $10(28.6)$ \\
Hepatotoxicity & $3(8.6)$ & $0(0.0)$ & $3(8.6)$ \\
Fatigue & $2(5.7)$ & $0(0.0)$ & $2(5.7)$ \\
Infection & $2(5.7)$ & $0(0.0)$ & $2(5.7)$ \\
Skin rash & $2(5.7)$ & $0(0.0)$ & $2(5.7)$ \\
Renal failure & $0(0.0)$ & $1(2.9)$ & $1(2.9)$ \\
Aching muscles and joints & $1(2.9)$ & $0(0.0)$ & $1(2.9)$ \\
Dry skin & $1(2.9)$ & $0(0.0)$ & $1(2.9)$ \\
Fever & $1(2.9)$ & $0(0.0)$ & $1(2.9)$ \\
Insomnia & $1(2.9)$ & $0(0.0)$ & $1(2.9)$ \\
Obstruction Gl - bowel & $1(2.9)$ & $0(0.0)$ & $1(2.9)$ \\
Oedema & $1(2.9)$ & $0(0.0)$ & $1(2.9)$ \\
\hline
\end{tabular}

Table 3. Reported grade 3 or 4 toxicities during bexarotene maintenance or within 30 days of stopping maintenance treatment, as-treated population

\begin{tabular}{|l|c|c|c|}
\hline & $\begin{array}{c}\text { Grade 3 } \\
(\mathbf{N}=\mathbf{2 4 )}\end{array}$ & $\begin{array}{c}\text { Grade 4 } \\
(\mathbf{N}=\mathbf{2 4 )}\end{array}$ & $\begin{array}{c}\text { Total } \\
(\mathbf{N}=\mathbf{2 4})\end{array}$ \\
\hline & No. (\%) & No. (\%) & No. (\%) \\
\hline $\begin{array}{l}\text { Any toxicity (each patient counted } \\
\text { once) }\end{array}$ & $5(20.8)$ & $1(4.2)$ & $6(25.0)$ \\
\hline $\begin{array}{l}\text { Any haematological toxicity (each } \\
\text { patient counted once) }\end{array}$ & $1(4.2)$ & $0(0.0)$ & $1(4.2)$ \\
\hline Anaemia & $1(4.2)$ & $0(0.0)$ & $1(4.2)$ \\
\hline Any non-haematological toxicity & $5(20.8)$ & $1(4.2)$ & $6(25.0)$ \\
(each patient counted once) & & & \\
\hline Hyperlipidaemia & $3(12.5)$ & $0(0.0)$ & $3(12.5)$ \\
Diarrhoea & $0(0.0)$ & $1(4.2)$ & $1(4.2)$ \\
Fatigue & $0(0.0)$ & $1(4.2)$ & $1(4.2)$ \\
Infection & $1(4.2)$ & $0(0.0)$ & $1(4.2)$ \\
Syncope & $1(4.2)$ & $0(0.0)$ & $1(4.2)$ \\
\hline
\end{tabular}

any diffuse erythema and induration) for at least 4 weeks, is much more subjective if the mSWAT analysis is not used. Against these criteria in $30 \mathrm{MF}$ patients (stage III or IV - no breakdown stated) a CR rate of $10 \%$ (3 of 30 patients) and a PR rate of $60 \%$ (18 of 30 patients) were described (Zinzani et al, 2000). The pivotal data for bexarotene also used the physicians Global Assessment and demonstrated response rates of 45\% (Duvic et al, 2001a).

While a large number of drugs show activity in CTCL there is no pathway for detailing the order they should be considered due to the lack of randomised controlled trials. When designing this phase II combination study the two drugs were selected as both showed activity in CTCL through different mechanisms of action 
and had non-overlapping toxicities. Given the reported activity of gemcitabine we anticipated rapid and effective initial tumour control followed by consolidation and maintenance of response with bexarotene. At the planned interim analysis, however, criteria for response were not fulfilled, and so the trial did not proceed to the second stage. There are a number of potential reasons as to why the response rate seen was lower than predicted. First, the trial population included a large number $(47.2 \%)$ of patients with erythrodermic disease, which is well recognised to run a more aggressive and refractory course. Indeed, the response rate at 12 weeks in the non-erythrodermic group was higher in the erythrodermic group (42\% vs 18\%). Second, in an effort to standardise measurement of disease response, all participating centres assessed disease burden with the internationally accepted mSWAT score (Olsen et al, 2011) and response could only be defined as such if OPDREC criteria (as used in US FDA pivotal romidepsin trial, where the efficacy assessment uses the summation of compartmental response; Whittaker et al, 2010) continued to be met 4 weeks later. This is a stricter disease assessment tool, which may have led to a lower number of patients meeting the formal response assessment for $\mathrm{PR}$. The response rate at 24 weeks reported in this study as the predefined primary objective fails to reflect the fact that most patients demonstrated some initial disease response after combination treatment (Figure 3), but then later progressed. This important observation of the discrepancy in the number of patients with improvement in mSWAT score who fail to meet conventional response criteria underlies the requirement in CTCL studies to use mSWAT. This finding is in keeping with a recently published phase II trial with the pan-deacetylase inhibitor panobinostat, which reported that $74.1 \%$ patients achieved a reduction in baseline mSWAT score, while only $17.3 \%$ could be classed as achieving disease response (Duvic et al, 2013). Finally, a potential antagonistic interaction between the two drugs when used in combination adversely decreasing the responses seen with either agent alone cannot be excluded.

Although $86 \%$ patients successfully completed four cycles of gemcitabine and bexarotene, control of serum triglycerides during this study was particularly challenging. Over $80 \%$ patients required a dose reduction or omission of bexarotene within the first 12 weeks despite treatment with fenofibrate before and during bexarotene treatment. Interestingly, this finding has been observed previously when bexarotene was added to gemcitabine/platinum combination in the treatment of non-small cell lung cancer. In this study, there were frequent dose adjustments and discontinuation of bexarotene, which necessitated an increase in the starting dose of atorvastatin. Despite this, $49 \%$ patients still experienced grade 3 or 4 hyperlipidaemia (Edelman et al, 2005). Taken together, in conjunction with our results, the data would strongly suggest that gemcitabine and bexarotene should not be administered together as it appears that gemcitabine interacts adversely with bexarotene to further increase lipids, which is problematic to manage even with optimal lipid-lowering therapy. Furthermore, the inevitable dose reductions and delays in bexarotene reduce dose intensity and therefore detract from the potential increased efficacy of using this combination of drugs. This finding of poor tolerance and lower efficacy of response in combination studies with bexarotene has previously been reported with vorinostat (Dummer et al, 2012a). The authors concluded that concomitant administration of vorinostat and bexarotene was feasible but only if lower doses of each drug were administered relative to the product label monotherapy doses.

An alternative strategy to potentially overcome the adverse effects of this concurrent combination therapy would be to debulk tumour first with gemcitabine or pegylated liposomal doxorubicin $+/$ - total skin electron beam therapy, followed sequentially by bexarotene maintenance treatment. However, when pegylated liposomal doxorubicin was used as initial cytoreducing chemotherapy followed by maintenance of bexarotene the initial responses of about $40 \%$ were lower than previously reported (Quereux et al, 2008) and the study did not demonstrate a benefit in terms of durability of response with bexarotene. One potential explanation for these lower response rates with such combination studies is patient selection and that inadvertently such studies have selected for highly aggressive, atypical patient populations. For example, patients with MF/SS suitable for chemotherapy but never having received bexarotene are unusual and indicative of early aggressive disease less likely to have durable responses to bexarotene (Strauss et al, 2011).

Completed QoL forms showed a general improvement in QoL scores and a significant decrease in itch as measured by VASs. Skindex Emotions, Symptoms and Functioning scales showed a significant improvement from baseline, although improved EORTC QLQ-C30 Functional scales and Global Health Status results did not reach statistical significance. Treatments for patients with CTCL are predominately palliative as no curative therapies are available. Stem cell transplant may offer the best chance of survival but transplant-related mortality is high (Guitart et al, 2002; Molina et al, 2005; Duarte et al, 2010; Duvic et al, 2010) therefore treatments should be aimed at minimising symptoms and improving QOL. Few studies have included robust measures of QOL and future studies should combine QOL with measures of tumour burden such as mSWAT scores to fully appreciate patient responses (Duvic et al, 2002).

In conclusion, the combination of gemcitabine and bexarotene did not meet the criteria to proceed to the second stage of the trial design, albeit that the majority of patients initially demonstrated some clinical response and improvement in QoL while on treatment. The response data would suggest that this combination should not be further investigated in this poor risk population. The response rates are lower than expected and these results may in part be substantially explained by the large proportion of patients included with erythrodermic disease. These results emphasise the importance of investigating combination of drugs with single agent activity that enters clinical practice with robust prospective clinical trials, rather than adopting combinations straight into clinical practice. This point is further emphasised by the finding that this drug combination appears to be poorly tolerated and adversely increased the lipid profile which led to a dose reduction in the bexarotene, particularly during the first 12 weeks. Further international collaborative studies looking at more defined populations, separating erythrodermic vs non-erythrodermic populations are required to make progress.

\section{ACKNOWLEDGEMENTS}

We would like to acknowledge funding towards the cost of bexarotene from Cephalon Limited, Cancer Research U.K. grant (A6657), NCRI Lymphoma Clinical Studies Group and finally all investigators, site staff and patients who participated in the trial.

\section{CONFLICT OF INTEREST}

TI, JS, SW and RC have performed consultancy with Cephalon and Teva.

\section{AUTHOR CONTRIBUTIONS}

TI, JS, SW and RC designed the trial. TI, SW, JS, DG, SM and RC performed the research. TI, NC, BP, PP, PS, CC, JS, SW and 
RC were involved in data analysis. All authors contributed to manuscript preparation.

\section{REFERENCES}

Abbott RA, Whittaker SJ, Morris SL, Russell-Jones R, Hung T, Bashir SJ, Scarisbrick JJ (2009) Bexarotene therapy for mycosis fungoides and Sezary syndrome. Br J Dermatol 160: 1299-1307.

Bunn Jr PA, Hoffman SJ, Norris D, Golitz LE, Aeling JL (1994) Systemic therapy of cutaneous T-cell lymphomas (mycosis fungoides and the Sezary syndrome). Ann Intern Med 121: 592-602.

Duarte RF, Canals C, Onida F, Gabriel IH, Arranz R, Arcese W, Ferrant A, Kobbe G, Narni F, Deliliers GL, Olavarria E, Schmitz N, Sureda A (2010) Allogeneic hematopoietic cell transplantation for patients with mycosis fungoides and Sezary syndrome: a retrospective analysis of the Lymphoma Working Party of the European Group for Blood and Marrow Transplantation. J Clin Oncol 28: 4492-4499.

Dummer R, Beyer M, Hymes K, Epping MT, Bernards R, Steinhoff M, Sterry W, Kerl H, Heath K, Ahern JD, Hardwick JS, Garcia-Vargas J, Baumann K, Rizvi S, Frankel SR, Whittaker SJ, Assaf C (2012a) Vorinostat combined with bexarotene for treatment of cutaneous T-cell lymphoma: in vitro and phase I clinical evidence supporting augmentation of retinoic acid receptor/retinoid $\mathrm{X}$ receptor activation by histone deacetylase inhibition. Leuk Lymphoma 53: 1501-1508.

Dummer R, Quaglino P, Becker JC, Hasan B, Karrasch M, Whittaker S, Morris S, Weichenthal M, Stadler R, Bagot M, Cozzio A, Bernengo MG, Knobler R (2012b) Prospective International Multicenter Phase II trial of intravenous pegylated liposomal doxorubicin monochemotherapy in patients with stage IIB, IVA, or IVB advanced mycosis fungoides: final results from EORTC 21012. J Clin Oncol 30: 4091-4097.

Duvic M (2000) Bexarotene and DAB(389)IL-2 (denileukin diftitox, ONTAK) in treatment of cutaneous T-cell lymphomas: algorithms. Clin Lymphoma 1(Suppl 1): S51-S55.

Duvic M, Donato M, Dabaja B, Richmond H, Singh L, Wei W, Acholonu S, Khouri I, Champlin R, Hosing C (2010) Total skin electron beam and non-myeloablative allogeneic hematopoietic stem-cell transplantation in advanced mycosis fungoides and Sezary syndrome. J Clin Oncol 28: 2365-2372.

Duvic M, Dummer R, Becker JC, Poulalhon N, Ortiz Romero P, Grazia Bernengo M, Lebbe C, Assaf C, Squier M, Williams D, Marshood M, Tai F, Prince HM (2013) Panobinostat activity in both bexarotene-exposed and -naive patients with refractory cutaneous T-cell lymphoma: Results of a phase II trial. Eur J Cancer 49(2): 386-394.

Duvic M, Hymes K, Heald P, Breneman D, Martin AG, Myskowski P, Crowley C, Yocum RC (2001a) Bexarotene is effective and safe for treatment of refractory advanced-stage cutaneous T-cell lymphoma: multinational phase II-III trial results. J Clin Oncol 19: 2456-2471.

Duvic M, Kuzel TM, Olsen EA, Martin AG, Foss FM, Kim YH, Heald PW, Bacha P, Nichols J, Liepa A (2002) Quality-of-life improvements in cutaneous T-cell lymphoma patients treated with denileukin diftitox (ONTAK). Clin Lymphoma 2: 222-228.

Duvic M, Martin AG, Kim Y, Olsen E, Wood GS, Crowley CA, Yocum RC (2001b) Phase 2 and 3 clinical trial of oral bexarotene (Targretin capsules) for the treatment of refractory or persistent early-stage cutaneous T-cell lymphoma. Arch Dermatol 137: 581-593.

Duvic M, Talpur R, Wen S, Kurzrock R, David CL, Apisarnthanarax N (2006) Phase II evaluation of gemcitabine monotherapy for cutaneous T-cell lymphoma. Clin Lymphoma Myeloma 7: 51-58.

Edelman MJ, Smith R, Hausner P, Doyle LA, Kalra K, Kendall J, Bedor M, Bisaccia S (2005) Phase II trial of the novel retinoid, bexarotene, and gemcitabine plus carboplatin in advanced non-small-cell lung cancer. J Clin Oncol 23: 5774-5778.

Guitart J, Wickless SC, Oyama Y, Kuzel TM, Rosen ST, Traynor A, Burt R (2002) Long-term remission after allogeneic hematopoietic stem cell transplantation for refractory cutaneous T-cell lymphoma. Arch Dermatol 138: $1359-1365$.

Jaffe ES, Harris NL, Stein H, Wardiman JW (2001) Pathology and genetics of tumours of the haematopoietic and lymphoid tissues. In The World health
Organisation Classification of Tumours. IARC Press: Lyon, France

Kim YH, Chow S, Varghese A, Hoppe RT (1999) Clinical characteristics and long-term outcome of patients with generalized patch and/or plaque (T2) mycosis fungoides. Arch Dermatol 135: 26-32.

Kurzrock R, Pilat S, Duvic M (1999) Pentostatin therapy of T-cell lymphomas with cutaneous manifestations. J Clin Oncol 17: 3117-3121.

Marchi E, Alinari L, Tani M, Stefoni V, Pimpinelli N, Berti E, Pagano L, Bernengo MG, Zaja F, Rupoli S, Pileri S, Baccarani M, Zinzani PL (2005) Gemcitabine as frontline treatment for cutaneous T-cell lymphoma: phase II study of 32 patients. Cancer 104: 2437-2441.

Molina A, Zain J, Arber DA, Angelopolou M, O’Donnell M, Murata-Collins J, Forman SJ, Nademanee A (2005) Durable clinical, cytogenetic, and molecular remissions after allogeneic hematopoietic cell transplantation for refractory Sezary syndrome and mycosis fungoides. J Clin Oncol 23: 6163-6171.

Olsen EA, Whittaker S, Kim YH, Duvic M, Prince HM, Lessin SR, Wood GS, Willemze R, Demierre MF, Pimpinelli N, Bernengo MG, Ortiz-Romero PL, Bagot M, Estrach T, Guitart J, Knobler R, Sanches JA, Iwatsuki K, Sugaya M, Dummer R, Pittelkow M, Hoppe R, Parker S, Geskin L, Pinter-Brown L, Girardi M, Burg G, Ranki A, Vermeer M, Horwitz S, Heald P, Rosen S, Cerroni L, Dreno B, Vonderheid EC (2011) Clinical end points and response criteria in mycosis fungoides and Sezary syndrome: a consensus statement of the International Society for Cutaneous Lymphomas, the United States Cutaneous Lymphoma Consortium, and the Cutaneous Lymphoma Task Force of the European Organisation for Research and Treatment of Cancer. J Clin Oncol 29: 2598-2607.

Quereux G, Marques S, Nguyen JM, Bedane C, D'Incan M, Dereure O, Puzenat E, Claudy A, Martin L, Joly P, Delaunay M, Beylot-Barry M, Vabres P, Celerier P, Sasolas B, Grange F, Khammari A, Dreno B (2008) Prospective multicenter study of pegylated liposomal doxorubicin treatment in patients with advanced or refractory mycosis fungoides or Sezary syndrome. Arch Dermatol 144: 727-733.

Rosen ST, Foss FM (1995) Chemotherapy for mycosis fungoides and the Sezary syndrome. Hematol Oncol Clin North Am 9: $1109-1116$.

Saleh MN, LeMaistre CF, Kuzel TM, Foss F, Platanias LC, Schwartz G, Ratain M, Rook A, Freytes CO, Craig F, Reuben J, Sams MW, Nichols JC (1998) Antitumor activity of DAB389IL-2 fusion toxin in mycosis fungoides. J Am Acad Dermatol 39: 63-73.

Simon R (1989) Optimal two-stage designs for phase II clinical trials. Control Clin Trials 10: 1-10.

Stevens SR, Ke MS, Parry EJ, Mark J, Cooper KD (2002) Quantifying skin disease burden in mycosis fungoides-type cutaneous T-cell lymphomas: the severity-weighted assessment tool (SWAT). Arch Dermatol 138 $42-48$.

Strauss DJ, Horwitz SM, Hymes KB, Goy A, Hernandez-Ilizaliturri FJ, Feldman T, Wegner B, Myskowski P (2011) Final results of phase ii trial of pegylated liposomal doxorubicin (PLD) followed by bexarotene (Bex) in advanced cutaneous T-cell lymphoma (CTCL). ASH: San Diego.

Weinstock MA, Horm JW (1988) Mycosis fungoides in the United States. Increasing incidence and descriptive epidemiology. JAMA 260: 42-46.

Whittaker SJ, Demierre MF, Kim EJ, Rook AH, Lerner A, Duvic M, Scarisbrick J, Reddy S, Robak T, Becker JC, Samtsov A, McCulloch W, Kim YH (2010) Final results from a multicenter, international, pivotal study of romidepsin in refractory cutaneous T-cell lymphoma. J Clin Oncol 28: 4485-4491.

Zackheim HS, Epstein Jr EH (1989) Low-dose methotrexate for the Sezary syndrome. J Am Acad Dermatol 21: 757-762.

Zinzani PL, Baliva G, Magagnoli M, Bendandi M, Modugno G, Gherlinzoni F, Orcioni GF, Ascani S, Simoni R, Pileri SA, Tura S (2000) Gemcitabine treatment in pretreated cutaneous T-cell lymphoma: experience in 44 patients. J Clin Oncol 18: 2603-2606.

Zinzani PL, Venturini F, Stefoni V, Fina M, Pellegrini C, Derenzini E, Gandolfi L, Broccoli A, Argnani L, Quirini F, Pileri S, Baccarani M (2010) Gemcitabine as single agent in pretreated T-cell lymphoma patients: evaluation of the long-term outcome. Ann Oncol 21 : 860-863.

Supplementary Information accompanies this paper on British Journal of Cancer website (http://www.nature.com/bjc) 


\section{APPENDIX 1}

Table A1. Compliance to study drug, as-treated population

\begin{tabular}{|c|c|c|c|}
\hline $\begin{array}{l}\text { Time of } \\
\text { study treatment }\end{array}$ & $N=35$ & $\begin{array}{c}\text { No dose } \\
\text { reduction, } \\
\text { delay or omission }\end{array}$ & $\begin{array}{c}\text { Median } \\
(\mathrm{p} 25, \mathrm{p} 75) \\
\text { dose in } \mathrm{mg}\end{array}$ \\
\hline \multicolumn{4}{|c|}{ Gemcitabine treatment $\left(1000 \mathrm{mg} \mathrm{m}^{-2}\right)$} \\
\hline $\begin{array}{l}\text { Cycle } 1 \text { day } 1 \\
\text { Cycle } 1 \text { day } 8 \\
\text { Cycle } 2 \text { day } 1 \\
\text { Cycle } 2 \text { day } 8 \\
\text { Cycle } 3 \text { day } 1 \\
\text { Cycle } 3 \text { day } 8 \\
\text { Cycle } 4 \text { day } 1 \\
\text { Cycle } 4 \text { day } 8\end{array}$ & $\begin{array}{l}35 \\
35 \\
34 \\
34 \\
31 \\
31 \\
30 \\
30\end{array}$ & $\begin{array}{l}35(100.0 \%) \\
29(82.9 \%) \\
29(85.3 \%) \\
24(70.6 \%) \\
29(93.5 \%) \\
24(77.4 \%) \\
25(83.3 \%) \\
24(80.0 \%)\end{array}$ & $\begin{array}{l}1900(1800,2000) \\
1900(1600,2000) \\
1900(1700,2000) \\
1793(1000,2000) \\
1900(1600,2000) \\
1824(1500,1976) \\
1900(1520,2000) \\
1812(1500,2000)\end{array}$ \\
\hline \multicolumn{4}{|c|}{ Bexarotene treatment ( $150 \mathrm{mg} \mathrm{m}^{-2}$ weeks $1 \& 2,300 \mathrm{mg} \mathrm{m}^{-2}$ thereafter) } \\
\hline $\begin{array}{l}\text { Cycle } 1 \text { week } 1 \\
\text { Cycle } 1 \text { week } 2 \\
\text { Cycle } 1 \text { week } 3 \\
\text { Cycle } 2 \text { weeks 4-6 } \\
\text { Cycle } 3 \text { weeks } 7-9 \\
\text { Cycle } 4 \text { weeks } 10-12 \\
\text { Maintenance weeks } 13-16 \\
\text { Maintenance weeks } 17-20 \\
\text { Maintenance weeks } 21-24 \\
\text { Maintenance weeks } 25+\end{array}$ & $\begin{array}{l}35 \\
35 \\
35 \\
34 \\
31 \\
30 \\
24 \\
20 \\
15 \\
12 \\
\end{array}$ & $\begin{array}{r}31(88.6 \%) \\
32(91.4 \%) \\
18(51.4 \%) \\
14(41.2 \%) \\
13(41.9 \%) \\
13(43.3 \%) \\
15(62.5 \%) \\
12(60.0 \%) \\
9(60.0 \%) \\
3(25.0 \%) \\
\end{array}$ & $\begin{array}{l}2100(1680,2100) \\
21100(1680,2100) \\
2310(2100,4200) \\
2775(1575,3675) \\
3150(2100,3675) \\
2700(1575,3360) \\
2700(2100,3675) \\
3150(2363,3675) \\
3150(2100,3675) \\
2713(1350,4200)\end{array}$ \\
\hline
\end{tabular}

\section{APPENDIX 2}

Table A2. Quality of life, as-treated population

\begin{tabular}{|c|c|c|c|c|c|}
\hline Visit & $N=35$ & $\begin{array}{l}\text { VAS median } \\
(\mathrm{p} 25, \mathrm{p} 75)\end{array}$ & $\begin{array}{l}\text { SKINDEX Emotions } \\
\text { median }(\mathrm{p} 25, \mathrm{p} 75)\end{array}$ & $\begin{array}{l}\text { SKINDEX Symptoms } \\
\text { median }(\mathrm{p} 25, \mathrm{p} 75)\end{array}$ & $\begin{array}{l}\text { SKINDEX Function } \\
\text { median }(\mathrm{p} 25, \mathrm{p} 75)\end{array}$ \\
\hline Baseline & 27 & $7.50(6.50,9.50)$ & $55.0(42.5,75.0)$ & $67.9(57.1,78.6)$ & $55.2(31.3,70.8)$ \\
\hline Cycle 1 weeks 1-3 & 24 & $7.50(5.50,8.50)$ & $55.0(30.0,65.0)$ & $64.3(46.4,75.0)$ & $50.0(29.2,72.9)$ \\
\hline Cycle 2 weeks 4-6 & 16 & $6.75(3.25,7.50)$ & $51.3(32.5,76.3)$ & $62.5(42.9,78.6)$ & $59.1(24.0,77.1)$ \\
\hline Cycle 3 weeks 7-9 & 17 & $5.50(3.50,7.50)$ & $47.5(22.5,72.5)$ & $46.4(35.7,67.9)$ & $41.7(16.7,68.8)$ \\
\hline Cycle 4 weeks 10-12 & 19 & $7.00(5.00,8.00)$ & $40.8(17.5,75.0)$ & $57.1(39.3,67.9)$ & $47.7(16.7,75.0)$ \\
\hline Maintenance weeks 13-16 & 11 & $6.50(2.50,7.50)$ & $38.9(10.0,55.0)$ & $57.1(28.6,75.0)$ & $35.4(18.8,75.0)$ \\
\hline Maintenance weeks $17-20$ & 10 & $6.00(1.50,8.50)$ & $32.5(25.0,52.8)$ & $35.7(21.4,78.6)$ & $42.7(18.8,52.1)$ \\
\hline Maintenance weeks $21-24$ & 11 & $4.50(2.50,8.50)$ & $32.5(20.0,62.5)$ & $35.7(25.0,50.0)$ & $35.4(14.6,54.2)$ \\
\hline
\end{tabular}

\begin{tabular}{|c|c|c|c|c|c|c|c|}
\hline Visit & $N=35$ & $\begin{array}{c}\text { Global Health } \\
\text { Status median } \\
(\mathrm{p} 25, \mathrm{p} 75)\end{array}$ & $\begin{array}{l}\text { Physical function- } \\
\text { ing median } \\
(\mathrm{p} 25, \mathrm{p} 75)\end{array}$ & $\begin{array}{l}\text { Role function- } \\
\text { ing median } \\
(\mathrm{p} 25, \mathrm{p} 75)\end{array}$ & $\begin{array}{c}\text { Emotional } \\
\text { functioning median } \\
(\mathrm{p} 25, \mathrm{p} 75)\end{array}$ & $\begin{array}{l}\text { Cognitive function- } \\
\text { ing median } \\
(\mathrm{p} 25, \mathrm{p} 75)\end{array}$ & $\begin{array}{c}\text { Social function- } \\
\text { ing } \\
\text { median } \\
(\mathbf{p} 25, \mathrm{p} 75)\end{array}$ \\
\hline Baseline & 27 & $50.0(33.3,66.7)$ & $66.7(60.0,93.3)$ & $50.0(16.7,66.7)$ & $66.7(33.3,83.3)$ & $66.7(50.0,83.3)$ & $66.7(33.3,100.0)$ \\
\hline Cycle 1 weeks 1-3 & 24 & $62.5(33.3,79.2)$ & $70.0(53.3,86.7)$ & $33.3((8.3,83.3)$ & $66.7(45.8,83.3)$ & $66.7(50.0,83.3)$ & $66.7(33.3,83.3)$ \\
\hline Cycle 2 weeks $4-6$ & 16 & $50.0(33.3,66.7)$ & $60.0(43.3,74.2)$ & $33.3(0.0,83.3)$ & $66.7(50.0,91.7)$ & $66.7(66.7,83.3)$ & $66.7(33.3,83.3)$ \\
\hline Cycle 3 weeks 7-9 & 17 & $58.3(50.0,83.3)$ & $73.3(53.3,86.7)$ & $50.0(33.3,66.7)$ & $66.7(66.7,91.7)$ & $83.3(66.7,83.3)$ & $66.7(33.3,83.3)$ \\
\hline Cycle 4 weeks $10-12$ & 19 & $58.3(33.3,66.7)$ & $80.0(46.7,91.7)$ & $58.3(33.3,66.7)$ & $66.7(41.7,83.3)$ & $66.7(50.0,100.0)$ & $50.0(33.3,83.3)$ \\
\hline $\begin{array}{l}\text { Maintenance weeks } \\
13-16\end{array}$ & 11 & $66.7(50.0,75.0)$ & $86.7(40.0,93.3)$ & $66.7(33.3,100.0)$ & $83.3(33.3,91.7)$ & $75.0(66.7,83.3)$ & $100.0(50.0,100.0)$ \\
\hline $\begin{array}{l}\text { Maintenance weeks } \\
17-20\end{array}$ & 10 & $62.5(41.7,75.0)$ & $83.3(73.3,93.3)$ & $66.7(50.0,100.0)$ & $91.7(58.3,100.0)$ & $83.3(66.7,100.0)$ & $66.7(50.0,100.0)$ \\
\hline $\begin{array}{l}\text { Maintenance weeks } \\
21-24\end{array}$ & 11 & $66.7(50.0,83.3)$ & $73.3(46.7,100.0)$ & $66.7(16.7,100.0)$ & $75.0(66.7,100.0)$ & $83.3(33.3,100.0)$ & $83.3(33.3,100.0)$ \\
\hline
\end{tabular}

